\title{
Propulsion System Analysis For Solar-Powered Electric Water Recreational
}

\author{
Sunaryo ${ }^{1, *}$, Dendi Nurachman ${ }^{2}$ \\ ${ }^{1}$ Naval Architecture and Marine Engineering Study Program, Department of Mechanical Engineering, Universitas Indonesia, Temple \\ Depok, 16424, Indonesia \\ ${ }^{2}$ Naval Architecture and Marine Engineering Study Program, Department of Mechanical Engineering, Universitas Indonesia, Temple \\ Depok, 16424, Indonesia
}

\begin{abstract}
Indonesia is the world's largest archipelago with more than 17,000 islands, and also the best marine tourism destination, there are many beautiful beaches and underwater spots throughout the country. Due to this potential condition Indonesian government is planning to improve its maritime tourism sector. To realize this boats play very important role both for transport as well as for recreational purposes. On the other hand the government is also committed to reduce the global warming from the use of fossil fuel especially in industry and transportation through the Presidential Regulation no. 61/2011, with the strategy for replacing the fossil fuel with renewable energy. To support the government's program the research is aimed to design solar-powered electric recreation boat for tourism, with the consideration that there is almost non-stop sun shine available all year long in Indonesia. The boat has length of 12 meters. In this paper the focus is on the analysis of the propulsion system of the boat, which consists of the calculation the power needed to run the electric motor, the optimum propeller design, and the steering system.
\end{abstract}

\section{Introduction}

The area of sea versus the land area in the world reaches approximately $70 \%$ to $30 \%$; it makes a challenge for countries in the world that have the sea and waters such as lakes and rivers to promote their maritime sector. As a maritime country with more than $60 \%$ area covered by sea and largest archipelago country with more than 17,000 islands, Indonesia have the best marine tourism destination due to its beautiful beaches and underwater spot. It is comparable that in the recent years, Indonesia has emerged as one of the most favorite tourist destination. With this positive growth from tourism aspect, the potential development of a water transportation vehicle that works on clean energy also emerged. But most of the water transportation in Indonesia such as recreational boat, fishing boat, and restaurant boat is still using fossil fuels, which this sector is the highest contributor to the global warming effect.

In recent years, global warming effect is a major problem in almost all parts of the world including Indonesia. These conditions trigger the Indonesian government to research on renewable energy field as a substitute for fossil energy in order to reduce the occurrence of global warming effect. Based on Minister of Energy and Mineral Resources Regulation no. $17 / 2013$ states that one of the potential renewable energy that can be used in Indonesia is solar energy... One of the renewable energy that can be used in Indonesia is solar energy, because Indonesian geographical location along the equator and has a high intensity of sunlight, that means it has excellent solar energy availability (Handayani, 2012).

In attempt to increase Indonesia's tourism aspect in maritime sector, and replace the use fossil fuel to solar energy, this research's objective is to design a solar power electric recreational boat, which has a $12 \mathrm{~m}$ length. This research is a further development of the solar boat created by Universitas Indonesia's team that participated in International Solar Boat Challenge competition held in the Netherlands.

The most important thing in building a solar powered boat is the efficiency of the electricity (Gorter, 2014), to ensure the electric motor propulsion have a good efficiency to produce effective power to propel the boat with the desired speed service and have a long time period. Propulsion system is one the most important thing to make an efficient solar-powered boat. This paper is focused onto the design propulsion system of the boat, propulsion system is divided into electric motor, propeller, and steering system. For the electric motor, the type of motor that is most suitable for the purpose is determined, and power needed to propel the boat with the boat's speed service is calculated. For the propeller, the type of propeller characteristic is calculated for the boat. Then, followed by designing the steering system that will be used for the boat to man oeuvre.

\section{Methodology}

Corresponding author: naryo@eng.ui.ac.id 


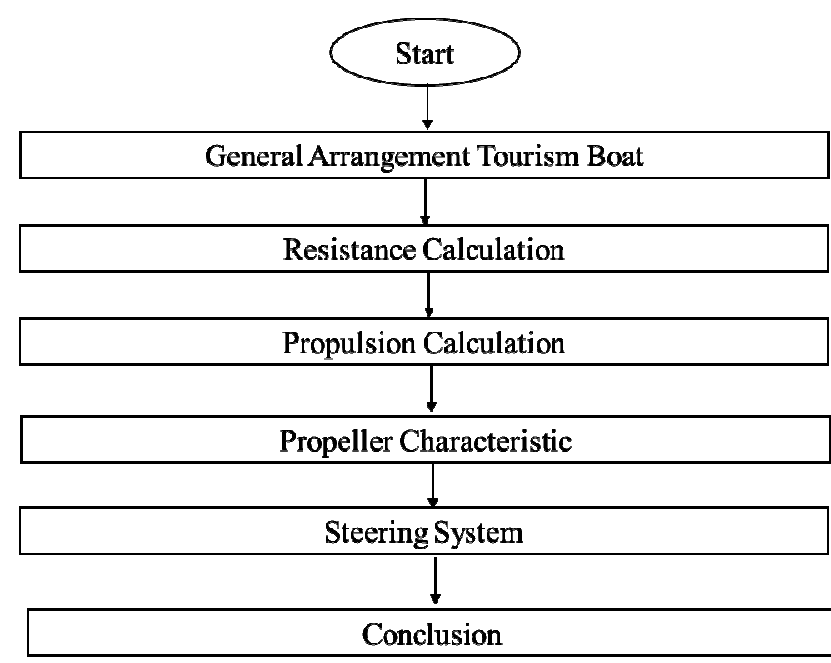

Fig. 1. Methodology chart

The methodology of this research's is shown in figure 1 from start until conclusion. The first methodology in this research is determine the dimensions and specification of the solar poweredelectric water recreational boat, with the main particulars as shown in table 1

Table 1. General Arrangement Boat.

\begin{tabular}{|c|c|}
\hline Parameter & Result \\
\hline Ship Type & Catamaran tourism boat \\
\hline Maximum Speed & $12 \mathrm{~m}$ \\
\hline Maximum Cruising Time & $\begin{array}{c}3-4 \text { hours continuous } \\
\text { operation }\end{array}$ \\
\hline Length over all & $5.4 \mathrm{~m}$ \\
\hline Width moulded & $0.7 \mathrm{~m}$ \\
\hline Draft at full load & 14 persons \\
\hline Passengers & $48 \mathrm{~V}$ \\
\hline Battery capacity & \\
\hline
\end{tabular}

Catamaran hull is selected in order to get good stability and to ensure space availability for all equipment's installation on the boat. This recreational boat is especially for hoping island trip that has a maximum speed of 6 knots and can cruise along the sea for 3-4 hours continuously with 14 passengers so the design is shown in figure 2 . From these data then can be known the dimension coefficient of recreational boats such as block coefficient is 0,64 and prismatic coefficient is 0,726. After that is used as an early reference to the design and calculation of propulsion systems, and then combined with literature study and discussion with experts so as to get more accurate results.

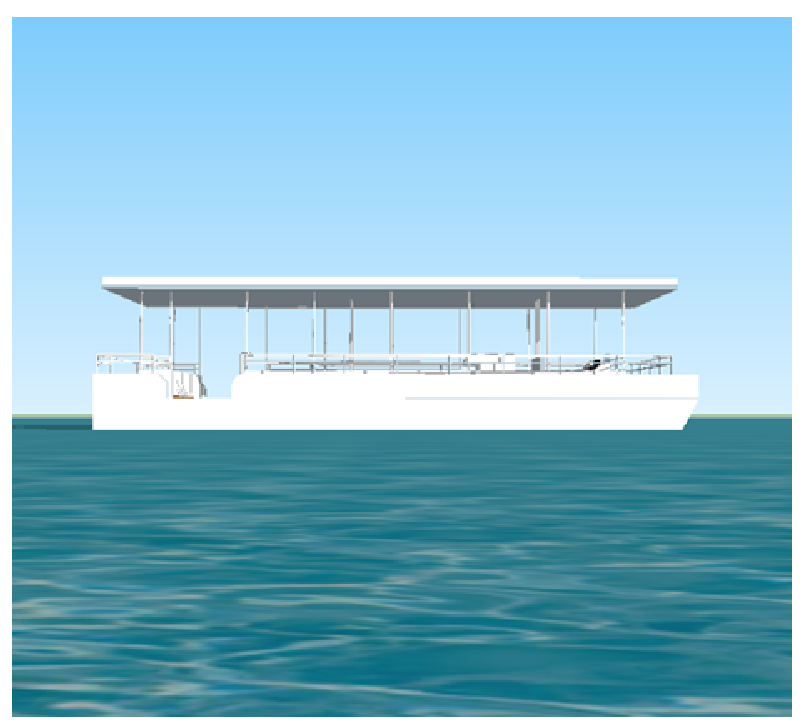

Fig. 2. UI's Solar Powered Boat

\section{Results}

\subsection{Resistance}

In this method, Calculation of resistance on recreational vessel using maxsurf resistance software method with correction approach formula based on harvalds method is calculated. Resistance is the force that occurs as a result of the fluid flow on the hull when ship is moving. To get the force of resistance, the propulsion system that will be used for solar boat is determined. The first step is calculated surface area below waterline of boat. The result from 3D maxsurf software is shown in table 2 , from this table the $3 \mathrm{~d}$ surface area is divided into 6 part and the total result is $42,3 \mathrm{M}^{2}$. The result is then corrected by approach using equation (1) where the result of that is close to $42 \mathrm{M}^{2}$. From these results then obtained an error between the results of the manual using the equation with the results using software $0.7 \%$.

Table 2. 3D surface area from maxsurf software.

\begin{tabular}{|c|c|}
\hline Hull Part & Area \\
\hline Outer Bottom $\left(\mathrm{M}^{2}\right)$ & 15.99 \\
\hline Outer Topsides $\left(\mathrm{M}^{2}\right)$ & 4.87 \\
\hline Tunnel Radius $\left(\mathrm{M}^{2}\right)$ & 4.87 \\
\hline Tunnel $\left(\mathrm{M}^{2}\right)$ & 0 \\
\hline Inner Bottom $\left(\mathrm{M}^{2}\right)$ & 16.55 \\
\hline Total Below DWL 3D $\left(\mathrm{M}^{2}\right)$ & $42.3 \mathrm{~m}$ \\
\hline & \\
\hline
\end{tabular}




$$
S\left[m^{2}\right]=1.025 \operatorname{Lpp}[m](C b \times B[m]+1.7 T[m]
$$

Where: $\mathrm{S}$ is Surface area below waterline; Lpp is Length perpendicular boat; $\mathrm{Cb}$ is Block Coefficient; $\mathrm{B}$ is Breadth boat; and $\mathrm{T}$ is Draft boat.

Next step is calculated total resistance coefficient (CT) of recreational boat; $\mathrm{CT}$ is calculated based on the respective coefficient of resistance which consists of coefficient of friction resistance, wave resistance coefficient, and additional resistance coefficient. CT is affected by the Reynolds number and the Froude number, both of which are influenced by the speed of the vessel, the result corresponding between total resistance coefficient and velocity of ship is shown in figure 3 . After that, the total resistance of the recreational boat is calculated. This total resistance is obtained by using equation (2) and the result is corrected using the maxsurf resistance software, so the results obtained are shown in figure 4 .

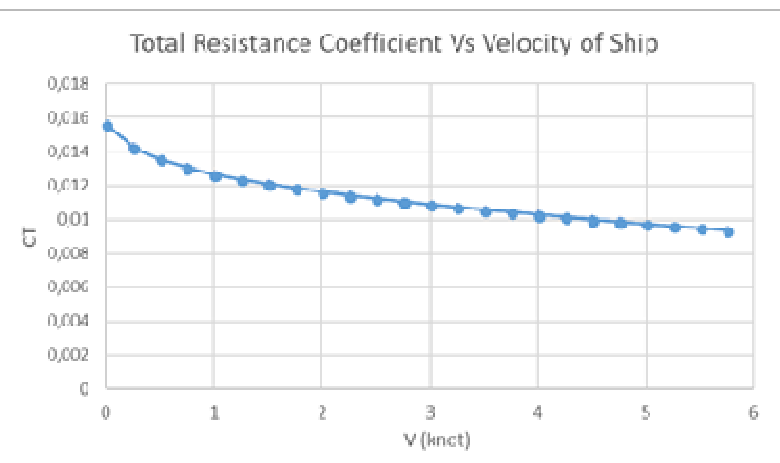

Fig. 3. CT vs Velocity of Ship

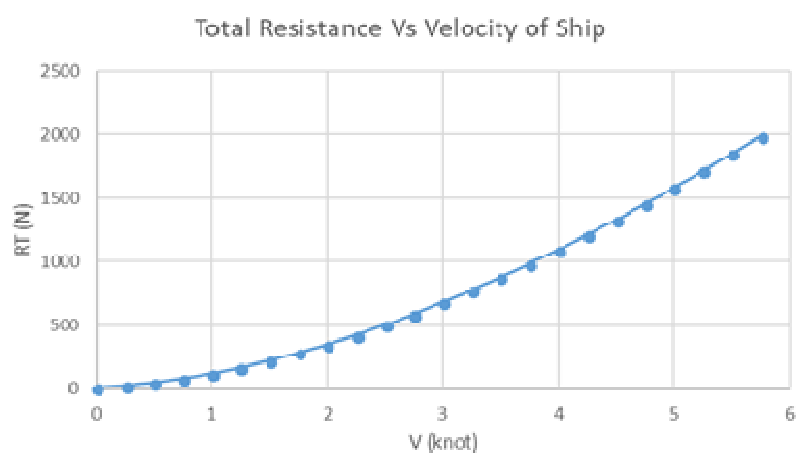

Fig. 4. Total Resistance vs Velocity of Ship

$$
R T[N]=\frac{1}{2} \times \rho\left[\frac{\mathrm{kg}}{\mathrm{m}^{3}}\right] \times C T[N] \times S\left[\mathrm{~m}^{2}\right] \times V s^{2}\left[\frac{\mathrm{m}}{\mathrm{s}}\right]
$$

Where: RT is Total Resistance; $\rho$ is Density of Sea Water; CT is Total Resistance Coefficient; and Vs is Velocity of Boat

The results obtained that the total resistance of recreational boat at a maximum speed is 1989 N. From Figure 4 it shows an increase in the graph so it can be said that the total resistance on the recreational boat is directly proportional to the velocity of the boat.

\subsection{Propulsion}

Propulsion is a mechanical system that will provide a force against the body of the ship so that the ship can go with the desired speed service. The first step is dertermining that the recreational boat uses single screw propulsion because the single screw uses only one main engine and one propeller so that it can minimize the use of space on the vessel. Power effective of the vessel (PE) is calculated using equation (3), and then the result is calculated with different speed variations so that it is shown in figure 5. From the figure it is shown that the velocity of the vessel is proportional to the ship's effective power required.

$$
P E[W]=R T[N] \times V s\left[\frac{m}{s}\right]
$$

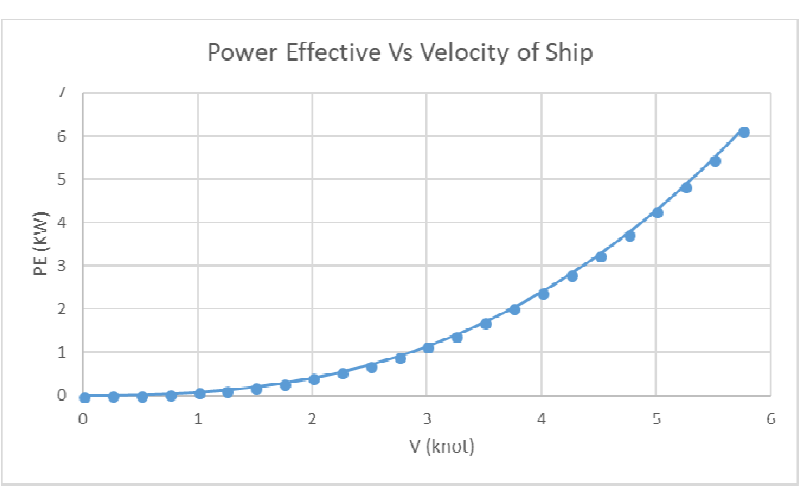

Fig. 5. Power Effective vs Velocity of Ship

Then the next step is to calculate the actual thrust force (Ta) and advance speed $(v \alpha)$ on the recreational boat. The actual thrust is a fluid force generated by propeller rotation to drive the vessel, Thrust is affected by the amount of thrust deduction factor (w). while the thrust deduction factor is a factor correction of the thrust force due to the longitudinal form of the hull itself. The advance velocity $(v \alpha)$ represents the velocity of the water flow shortly after entering the propeller due to propeller rotation, the advance velocity is affected by the wake factor (w), and the factor wake is the nondimensional factor used to estimate the fluid velocity that will enter the propeller. The results obtained are shown in table 3 .

Table 3. Characteristics Propulsion

\begin{tabular}{|c|c|c|}
\hline Parameter & Equation & Result \\
\hline Wake factor & $\mathrm{w}=0.7 \mathrm{Cp}-0,18$ & 0,28 \\
\hline Advance of speed & $\mathrm{Va}=(1-\mathrm{w}) \mathrm{Vs}[\mathrm{knot}]$ & 4,34 \\
\hline $\begin{array}{c}\text { Thrust deduction } \\
\text { factor }\end{array}$ & $\mathrm{t}=0.5 \mathrm{Cp}-0,18$ & 0,14 \\
\hline Thrust actual & $\mathrm{Ta}=\mathrm{Rt} /(1-\mathrm{t})[\mathrm{kN}]$ & 2,33 \\
\hline
\end{tabular}


The next calculation is to determine the optimal characteristics of propeller for the recreational boat; the calculations performed using the method on the wegeningen B series diagram. The first step is to determine the optimum diameter of the propeller (D) by using equation 4 , then recreational boat is a slow speed boat so that the use of slow rpm on the propeller has been determined, other than that the recreational boat requires optimal torque so the use of 4 blades on the propeller is better than the use of 3 blades or 2 blades. Then using equation 5 and equation 6 can determine the torque coefficient (KQ) and thrust coefficient (KT) of the propeller. While to determine the advance coefficient (J) of the propeller is calculated using equation 7. So from known propeller coefficients it can calculate the efficiency of open water propeller (

The efficiency of open water propeller is the efficiency of propeller when the propeller is in the flow free or not being behind the ship, the greater value of no is the better design of propulsion system, because in the design of propulsion, this efficiency is the least value when compared with other efficiency in the propulsion system. The next step is to plot propeller parameters on the wegeningen $b$ series diagram to get the pitch per diameter ratio $(\mathrm{P} / \mathrm{D})$ and the results are shown in Figure. 6. So that the optimum characteristics of the propeller can be seen in table 4 .

$$
\begin{aligned}
& D[M]=0.7 \times T[M] \\
& K Q=\frac{Q[\mathrm{Nm}]}{\rho\left[\frac{\mathrm{kg}}{\mathrm{m}^{3}}\right] \times n^{2}\left[\frac{1}{\mathrm{~s}}\right] \times D^{5}[\mathrm{~m}]} \\
& K T=\frac{T a[\mathrm{~N}]}{\rho\left[\frac{\mathrm{kg}}{\mathrm{m}^{3}}\right] \times n^{2}\left[\frac{1}{s}\right] \times D^{4}[\mathrm{~m}]} \\
& J=\frac{V a\left[\frac{\mathrm{m}}{\mathrm{s}}\right]}{n\left[\frac{1}{s}\right] \times D[\mathrm{~m}]} \\
& \eta o=\frac{K T \times J}{K Q \times 2 \times \pi}
\end{aligned}
$$

Where: D is Diameter Propeller; KQ is Torque Coefficient; KT is Thrust Coefficient; Q is Torque; Ta is Thrust; $\mathrm{n}$ is Rotation of Propeller; $\mathrm{J}$ is Advance Coefficient; Va is Advance of Speed; and no is Open Water Propeller Efficiency.

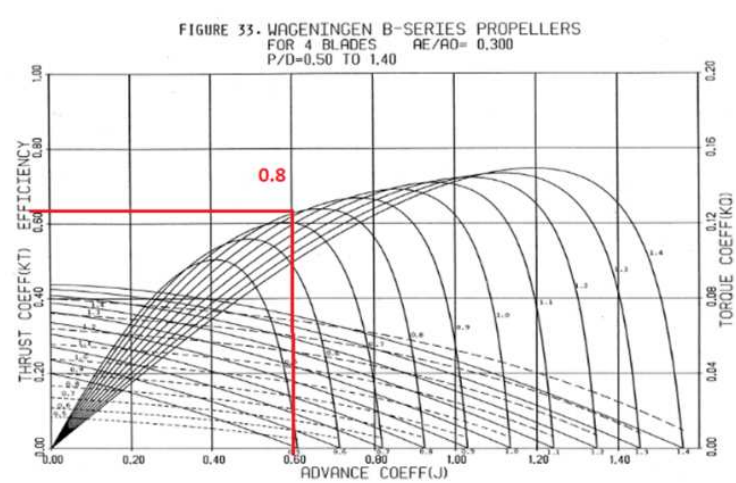

Fig. 6. Wegeningen B Series Propeller Diagram

Table 4. Optimum Characteristic Propeller for Boat

\begin{tabular}{|c|c|}
\hline Parameter & Result \\
\hline Diameter Propeller & $0.49 \mathrm{M}$ \\
\hline Number of Blades & 4 blades \\
\hline Propeller Rotation & 50 RPM \\
\hline Blade Area Ratio & 0.3 \\
\hline Pitch Diameter Ratio & 0.8 \\
\hline Torque Coefficient & 0.123 \\
\hline Thrust Coefficient & 0.82 \\
\hline Advance Coefficient & 0.60 \\
\hline Open Water Propeller & $64 \%$ \\
\hline Efficiency & \\
\hline
\end{tabular}

The next calculation is to determine the electric motor propulsion power (BHP) for recreational boat. In determining the electric motor propulsion, analyzing the efficiency contained in the system propulsion has been done so that obtained schematic propulsion power diagram shown in Figure 6. From Figure 6 it can be seen that propulsion power consists of EHP, THP, DHP, ElHP. then each magnitude of power is affected by the hull efficiency, the propeller efficiency, the relative rotation efficiency, and mechanical efficiency. Hull efficiency is the efficiency resulting from the hull form itself and can be calculated using equation 9 so that the result obtained is 0.94 . The efficiency of open water propeller is obtained from the characteristics propeller calculation and the result is 0.64 . Mechanical efficiency is the efficiency resulting from the vibration of the shafts and bearings present in the propulsion system and for the slow vessels it is assumed to be 0.98 . So the total 
efficiency of the propulsion system for recreational boat is 0.59 . Then from the previous calculation can be known electric motor propulsion power for recreational boat using the equation 10. And power for each parameter is shown in figure 7.

Electric
Motor El-HP Shaft $\sqrt{\text { Propeller }}$ THP $\sqrt{\text { Hull }}$ EHP

Fig. 7. Schematic Propulsion Power Diagram

$$
\begin{gathered}
\eta h=\frac{(1-t)}{(1-w)} \\
P M[W]=\frac{P E[W]}{\eta t}
\end{gathered}
$$

Where: PM is Electric Motor Power; PE is Effective Power; $\eta \mathrm{h}$ is Hull Efficiency; $\eta \mathrm{h}$ is Total Propulsion Efficiency, $t$ is thrust deduction factor, and $\mathrm{w}$ is wake factor

Table 5. Calculation Propulsion Power for Boat

\begin{tabular}{|c|c|}
\hline Parameter & Result \\
\hline EHP & $6.13 \mathrm{KW}$ \\
\hline THP & $6.52 \mathrm{KW}$ \\
\hline DHP & $10.18 \mathrm{KW}$ \\
\hline El-HP & $10.33 \mathrm{KW}$ \\
\hline
\end{tabular}

Based on the results from table 5 it can be determined the type of electric motor propulsion suitable for recreational boat is electric outboard propulsion 10 KW from Chinese manufacturers with the specifications shown in table 6. After that the motor has done a dynamic test to see the electric efficiency in each motor input power and the results are shown in figure 8

Table 6. Electric Motor Outboard Propulsion Specification

\begin{tabular}{|c|c|}
\hline Model & HPM48 \\
\hline Type & BLDC \\
\hline Weight & $48 \mathrm{Kg}$ \\
\hline Voltage & $48 \mathrm{~V}$ \\
\hline Torque & $29.2 \mathrm{Nm}$ \\
\hline Power & $1000 \mathrm{~W}$ \\
\hline Current & $250 \mathrm{~A}$ \\
\hline Efficiency & $87.5 \%$ \\
\hline
\end{tabular}

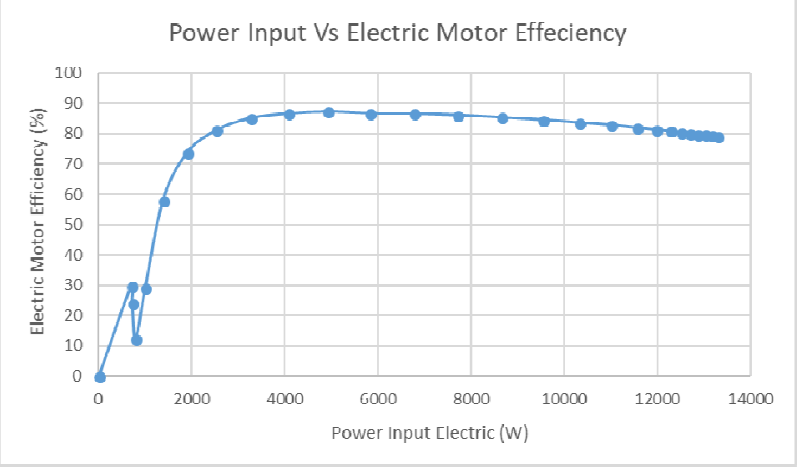

Fig. 8. Power Input vs Electric Motor Efficiency

Based on Figure 8, the graph shows that the electric motor input power for each electric current that flows into the motor at rated voltage $48 \mathrm{~V}$. From the data it is found that the highest efficiency occurs when the incoming electric current of $103 \mathrm{~A}$ with a potential difference of $47.3 \mathrm{~V}$ is equal to $87.5 \%$. At that time the input power into the electric motor is $4902 \mathrm{~W}$ and the resulting power output is $4291 \mathrm{~W}$. Then the power output value is used as the operational power for the solar powered electric water recreational boat when it operates carrying passengers, and at that time the speed of the ship is 4.3 knots. So it can be concluded that the speed is used as the operational speed of the ship.

\subsection{Steering System}

Steering system is a mechanical system that works on the ship to move the rudder and propeller so that the ship can maneuver. In analyzing the steering system used by solar powered electric recreational boat required calculations based on the BKI rules of $2006 \mathrm{vol}$ II so that the steering system is suitable for the vessel. The first step is to determine the minimum area of the ruder to be used, and can be calculated by using equation 11 . After that the next step is calculated the rudder force using equation 12. Then from the rudder force can be determined the amount of torque moment in rudder using equation 13. Based on the safety factor set by the BKI about the maximum rotation angle of the rudder on the vessel, it is assumed that on this recreational boat the rudder can rotate 45 degrees to the right or to the left with a rotate time of 5 seconds. So the next step can determine the power of the steering shaft for recreational boat using equation 13. then assumed in this steering system has efficiency of $20 \%$ then can be calculated power steering system for solar powered electric recreational boat using equation 15 . The result of the calculation of steering system can be seen in table 7 .

$$
\begin{aligned}
& A\left[\mathrm{~m}^{2}\right]=c \times\left(\frac{1.75 \times L p p[\mathrm{~m}] \times T[\mathrm{~m}]}{100}\right) \\
& C R[N]=132 \times A\left[\mathrm{~m}^{2}\right] \times V s^{2}\left[\frac{\mathrm{m}}{\mathrm{s}}\right] \times k
\end{aligned}
$$




$$
\begin{aligned}
& Q R[N m]=C R[N] \times r[m] \\
& N r s[H P]=\frac{Q R[N m] \times 2 \times \alpha[\mathrm{deg}] x \pi}{t[s] \times 180 \times 75} \\
& N r[H P]=N r s[H P] / \eta s
\end{aligned}
$$

Where: A is Surface Area of rudder; CR is Rudder Force; QR is Rudder Torque; Nrs is Steering Shaft Power; $\mathrm{Nr}$ is Steering System Power; c coefficient rudder form; $\mathrm{k}$ is coefficient rudder force; $r$ is coefficient of rudder lenght; $\alpha$ is rudder rotate; $t$ is rotate time of rudder; $\eta \mathrm{s}$ is steering system efficiency.

Table 7. Steering System Calculation Results

\begin{tabular}{|c|c|}
\hline Table 7. Steering System Calculation Results \\
\hline Parameter & Results \\
\hline A & $0.14 \mathrm{~m}^{2}$ \\
\hline $\mathrm{CR}$ & $678 \mathrm{~N}$ \\
\hline $\mathrm{QR}$ & $42.3 \mathrm{Nm}$ \\
\hline $\mathrm{Nrs}$ & $0.18 \mathrm{HP}$ \\
\hline $\mathrm{Nr}$ & $0.89 \mathrm{HP}$ \\
\hline
\end{tabular}

Based on the calculation of the steering system it can be determined the type of steering system suitable for solar powered electric water recreational boat is a hydraulic steering system. In determining the type of steering system the compatibility with the propulsion system need to be considered, some advantages of using a hydraulic steering system is that the force of pilots that need to turn the steering wheel and steer the ship is lighter, the space of engine room and cabin room can be reduced, and makes the mounting and maintenance much easier. Then the installation of hydraulic steering system shown in figure 9.
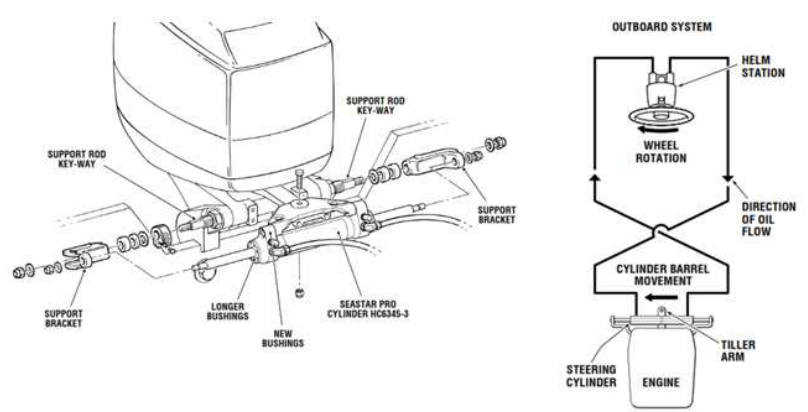

Fig. 9. Hydraulic Steering Installation

\section{Conclusion}

In designing a propulsion system on a solar powered electric water recreational boat. There are 3 sub system that is calculated that is resistance of the boat; propulsion of the boat; steering system of the boat. This solar power water recreational boat can carry 14 passengers with has a maximum speed of 6 knots and maximum cruising time 3-4 hours continuous operation.

The resistance of recreational boat has been calculated and the result at maximum speed is $1989 \mathrm{~N}$. From the graph resistance vs velocity its shows an increase so it can be said that the total resistance on the recreational boat is directly proportional to the velocity of the boat.

The propulsion of recreational boat has been calculated and the result of electric motor power at maximum speed is $10 \mathrm{KW}$. The optimum characteristics of propeller that can be suitable for recreational boat has been determined and the results for the optimum diameter of propeller is 0.49 meter with number of blades is 3 . The efficiency of the system propulsion has been calculated and the result is $59 \%$ so that means this propulsion system have good efficiency.

The outboard propulsion type has been chosen for the propulsion system, because it has advantage factor such as can save space of engine room, easy mounting, and flexible steering, moreover it can make better maneuverability for catamaran boats. The Hydraulic type steering system has been chosen for the Steering system, because it is easy in operation, easy installation, and does not require a large space.

With this result of propulsion analysis on the recreational boat, this solar powered electric recreational boat can be good candidate to be applied as a tourism boat in Indonesian water especially Bali Island.

\section{Acknowledgement}

The Authors would like to thank Directorate of Research and Community Engagement Universitas Indonesia for providing fund for finalizing the research and publishing its results through PITTA Project 2018 Contract number 2541/UN2.R3.1/HKP.05.00/2018.

\section{References}

1. Wiryawan, B., et al (1999). Lampung Coastal Resources Atlas. Government of Lampung Province and Coastal Resources Management Project. Coastal Resources Center, University of Rhode Island and Centre for Coastal and Marine Resources Studies, Bogor Agricultural University. Bandar Lampung. Indonesia 
2. Ministry of Environment. (2007). Rencana Aksi Nasional dalam Menghadapi Perubahan Iklim [National Action Plan in Mitigating Climate Change]. Ministry of Environment. Jakarta.

3. Mustafa, M.M. (2014). SOLAR ENERGY FOR RIVER NILE CRUISERS. Portal of Scientific Journals of Croatia. vol. 65 No. 2.

4. Handayani, N.A., et al (2012). Potency of Solar Energy Applications in Indonesia. International Journal of Renewable Energi Development, pp 33 38

5. Harvald S.A. (1983). Resistance and Propulsion of Ships. Department of Ocean Engineering, The techincal University of Denmark. John Wiley and Sons, pp $198-211$.

6. Kurniawan, A. (2016). A Review of Solar-Powered Boat Development. Journal for Technology and Science, vol. 27 No. 1. pp 1-8.

7. Gorter, T. (2015). Design considerations of a solar racing boat: propeller design parameters as a result of PV system power. Proceedings of The $7^{\text {th }}$ International Conference on Applied Energy, pp $1901-1906$

8. Spagnolo, G. S., et al (2012). Solar-Electric Boat. Journal of Transportation Technologies, vol. 2, pp $144-149$.

9. Xingrong, S., \& Yuejin, C. (2013). Study on Hydrodynamic Performance of Podded Propulsor at Steering Conditions. Proceedings of the Third International Symposium on Marine Propulsors. pp $358-363$.

10. Islam, M. F. et al (2009). Performance Charactecteristics of Static and Dynamic Azimuthing Podded Propulsor. Proceedings of the First International Symposium on Marine Propulsors, pp 482 - 492.

11. Lee, H. S. (2015). General Rainfall Patterns in Indonesia and The Potential Impacts of Local Seas on Rainfall Intensity. Basel: MDPI, Water Vol. 7, No. 4, pp $1751-1768$.

12. Krasilnikov, V. et al (2015). Investigation into the Influence of Reynold Number on Open Water Characteristics of Pod Propulsors. Proceedings of the Fourth International Symposium on Marine Propulsors. pp $710-720$.

13. Go, S. et al (2015). Study on the Powering Performance Evaluation for the Pod Propulsion Ships. Proceedings of the First International Symposium on Marine Propulsors. pp 105 - 111. 